\title{
Oral Health Status of Cirrhotic Patients in List of Liver Transplantation and of Viral Hepatitis Carriers
}

\author{
Liliane Lins ${ }^{1,2 *}$ and Antônio Fernando Pereira Falcao ${ }^{3}$
}

${ }^{1}$ Bahiana School of Medicine and Public Health, Salvador, Bahia, Brazil

${ }^{2}$ School of Medicine, Federal University of Bahia, Salvador, Bahia, Brazil

${ }^{3}$ School of Dentistry, Federal University of Bahia, Salvador, Bahia, Brazil

\begin{abstract}
Introduction: Infections are frequent causes of morbidity and mortality after liver transplantation and a major cause of decomposition in cirrhotic patients awaiting liver transplantation. Cirrhotic patients with poor oral health status may present increased susceptibility to systemic infections in the pre and/or post-operative liver transplantation period. Objective: To compare oral health status of liver transplantation patients with chronic viral hepatitis carriers.

Methods: This prospective, concurrent study included 66 patients, 45 males $(68.2 \%)$, observed from January, 2010 to December, 2011. Out of these 66 patients, $18(27 \%)$ were waiting for liver transplantation and $48(73 \%)$ were non-cirrhotic hepatitis patients: $16(24 \%)$ were Hepatitis C Virus carriers, 17 (26\%) Hepatitis B Virus carriers and $15(23 \%)$ non-HCV and non-HBV hepatitis. All patients were evaluated at the Stomatology Service from Federal University of Bahia. Oral health status evaluation was performed according to WHO Standards.

Results: Forty-seven patients $(71.2 \%)$ experienced reduced salivary flow. Patients in the liver transplantation group had more gingivitis $(p=0.04)$, periodontitis $(p=0.04)$ and a slightly higher DMFT (Decayed, Missing and Filled Teeth) mean (19.11) when compared with those with less severe liver disease. However, when comparing the liver transplantation group with non-cirrhotic HCV carriers, there was no statistical significance.
\end{abstract}

Conclusion: Liver transplantation patients have poorer oral health than patients with less severe hepatitis. Hepatitis $\mathrm{C}$ carriers also present severe periodontal disease, requiring stomatological preventive and curative intervention.

Keywords: Liver transplantation; Oral pathology; Oral health

\section{Introduction}

Infections are responsible for liver cirrhosis decomposition in patients awaiting liver transplantation. Infections are also a frequent cause of morbidity and mortality in patients with chronic liver disease $[1,2]$. Infection complications are also often seen after liver transplantation (LT), due to the additive effects of surgery, intensive care procedures and immunossupression [3]. Cirrhotic patients with poor oral health, particularly those with chronic infections such as abscesses, periapical lesions and periodontitis, are more susceptible to develop systemic infections [2-14]. In many cases, patients with liver failure, secondary to viral infection, present oral disorders due to the use of antiretroviral drugs, requiring a stomatologist in the medical staff in order to treat the systemic effects of oral disease [15]. The objective of the present study is to compare the oral health status of LT patients with that of chronic viral hepatitis carriers.

\section{Methods}

\section{Study Population}

This prospective, concurrent study included 66 patients, 45 males (68.2\%), attending to the Stomatology Service of the Faculty of Dentistry, Federal University of Bahia, Salvador, Bahia, Brazil, between January, 2010 and December, 2011. Age ranged 23-69 years, with mean 50.2 and median 52 . The following data were recorded: age, sex, skin color, education, income, cirrhosis etiology and dental care data. Liver Transplantation Patients and Less Severe Liver Disease Patients showed similar sociodemographic characteristics, except sex (Table 1).

Both extra-oral and intra-oral examinations were conducted and carious lesions were diagnosed by clinical examination and radiographs. Gingival index, probing depth and clinical attachment loss were measured by a periodontal probe in accordance with the European Association of Dental Public Health Standards. This organization criteria were used to define the severity of periodontitis
$[16,17]$. Numbers of decayed, missing and filled teeth were recorded by the DMFT index, according to WHO [18]. Salivary flow exams [19] classified a flow between 1 and $3 \mathrm{~mL} / \mathrm{min}$ as normal, while less than 1 $\mathrm{mL} / \mathrm{min}$ was considered to be reduced. The liver cirrhosis was analyzed in relation to the demographical, clinical and analytical variables using EPI-INFO 3.5.1 program. This study protocols were approved by the Ethical Review Board of the Faculty of Dentistry at Federal University of Bahia (FR: 345966, CAAE: 0018.0.368.000-10) and are in accordance with Brazilian National Health Council Resolution 196/96, as well as the Sixth Revision of the Declaration of Helsinki, 2008.

\section{Results}

Of the 66 patients, 18 (27\%) were waiting for LT and $48(73 \%)$ were non-cirrhotic hepatitis patients: 16 (24\%) Hepatitis C Virus carriers undergoing antiviral treatment, 17 (26\%) Hepatitis B Virus carriers and 15 (23\%) non-HCV and non-HBV hepatitis (idiopathic or autoimmune hepatitis). All diagnoses of liver disease were established by the Unit of Gastroenterology and Hepatology at Federal University of Bahia.

Concerning the group of the 18 patients waiting for LT, 33\% had liver cirrhosis secondary to $\mathrm{HCV}$ infection. Comparing patients in

*Corresponding author: Liliane Lins, Bahiana School of Medicine and Public Health, R. Frei Henrique, 8, Nazare, Salvador, Bahia CEP: 40050-420, Brazil, E-mail: lilianelinskusterer@bahiana.edu.br

Received November 17, 2012; Accepted December 21, 2012; Published December 26, 2012

Citation: Lins L, Pereira Falcao AF (2012) Oral Health Status of Cirrhotic Patients in List of Liver Transplantation and of Viral Hepatitis Carriers. J Transplant Technol Res 2:116. doi:10.4172/2161-0991.1000116

Copyright: ( 2012 Lins L, et al. This is an open-access article distributed unde the terms of the Creative Commons Attribution License, which permits unrestricted use, distribution, and reproduction in any medium, provided the original author and source are credited. 
the list of LT to patients with less severe LD, it was observed that the LT group had higher proportion of gingivitis $(\mathrm{p}=0.04)$, periodontitis $(0.04)$, as well as a slightly higher $(\mathrm{p}=0.13)$. DMFT-index mean of (19.11 versus 16.56). Radiographs of some selected patients from LT group are shown in Figure 1.

Patients from the LT group did not differ from those with noncirrhotic HCV carriers concerning the presence of gingivitis $(p=0.27)$ and periodontitis $(\mathrm{p}=0.12$ ), indicating that both groups had poor oral health. HBV carriers had better oral health status when compared to the other groups $(p=0.05)$. A total of $43(65.2 \%)$ individuals complained of chewing difficulties and $47(71.2 \%)$ patients experienced reduced salivary flow. The prevalence of soft tissue lesions is shown in Table 2. LT patients presented soft tissue oral lesions more frequently (33.3\%) than patients with less severe liver disease (12.6\%).

\section{Discussion}

Many factors may influence the evolution of periodontal disease, tooth decay and oral infections, like the lack of access to proper dental care, education level, and use of medications that may result in a reduction of salivary flow, stress, cognitive loss and depression [20-22]. In the present study, patients from both groups (Liver Transplantation or Less Severe Liver Disease) had similar sociodemographic characteristics.

The foci of odontogenic infections are not treated solely with antibiotic therapy. Effective treatment requires the removal of abscesses and intraosseous lesions, as well as treatment of periodontitis. Untreated foci, associated with poor level of oral hygiene, increase susceptibility to infection, especially in patients with a compromised overall health state, as well as those who are immunocompromised [1-3]. A case report of hepatic pyogenic abscess, probably caused by periodontal disease bacteria, corroborates this correlation [23]. Although the literature is not consistent with respect to a correlation between oral infection and pre- and post-transplant complications, a survey of 294 organ transplant clinics in the United States demonstrated the need for more concerted efforts with respect to patient oral health by multidisciplinary transplant teams [9].

The present study corroborates the literature $[2,4,6]$ that describes a high frequency of advanced periodontal disease and low rates of oral health in patients waiting for liver transplantation. However, the oral health of this group was similar to that of HCV carriers undergoing antiviral treatment, showing that both groups need attention to oral preventive and curative measures. These data are according to literature that correlates hepatitis $C$ infection [15] with a poor state of oral health.

Despite of the report of hemorrhagic complications in LCD patients [12], which contraindicates surgical treatment of these patients, the Stomatology Clinic, Faculty of Dentistry at Federal University of Bahia, has developed protocols to care for patients with liver cirrhosis. In most cases when surgery is required, extractions are performed in a hospital environment with administration of blood products, particularly in cases of severe liver disease. The postoperative period is accompanied

\begin{tabular}{|c|c|c|c|c|c|}
\hline \multirow{2}{*}{ Variables } & \multicolumn{2}{|c|}{ Liver Transplantation Patients } & \multicolumn{2}{|c|}{ Less Severe Liver Disease Patients } & \multirow[t]{2}{*}{ P-value } \\
\hline & $\mathrm{N}=18$ & $\%$ & $\mathrm{~N}=48$ & $\%$ & \\
\hline Sex & & & & & 0.003 \\
\hline Female & 1 & $(6.0)$ & 20 & $(42.0)$ & \\
\hline Male & 17 & $(94.0)$ & 28 & $(58.0)$ & \\
\hline \multicolumn{6}{|l|}{ Age (years) } \\
\hline 20 to 30 years & 2 & $(11.0)$ & 5 & $(10.0)$ & 0.257 \\
\hline 31 to 50 years & 4 & $(22.0)$ & 21 & $(44.0)$ & \\
\hline$>50$ years & 12 & $(67.0)$ & 22 & $(46.0)$ & \\
\hline Skin color & & & & & 0.615 \\
\hline White & 4 & $(22.0)$ & 11 & $(23.0)$ & \\
\hline Not White & 14 & (78.0) & 37 & $(77.0)$ & \\
\hline \multicolumn{6}{|c|}{ Education (years) } \\
\hline$\leq 8$ & 16 & (89) & 43 & (89) & 0.608 \\
\hline$>8$ & 2 & (11) & 5 & (11) & \\
\hline \multicolumn{6}{|l|}{ Income } \\
\hline$<1 \mathrm{MW}^{*}$ & 1 & (6.0) & 7 & $(15.0)$ & 0.152 \\
\hline 1-2 MW & 5 & $(28.0)$ & 22 & $(46.0)$ & \\
\hline$\geq 2-5 \mathrm{MW}$ & 10 & (55.0) & 18 & $(37.0)$ & \\
\hline$>5 \mathrm{MW}$ & 2 & (11.0) & 1 & $(2.0)$ & \\
\hline
\end{tabular}

${ }^{*} \mathrm{MW}=$ Minimum Wage, approximately US $\$ 299.00$

Table 1: Socio-demographic characteristics of the studied population.

\begin{tabular}{|c|c|c|c|c|}
\hline \multirow{2}{*}{ Soft tissue oral lesions } & \multicolumn{2}{|c|}{ Liver transplantation Patients $(n=18)$} & \multicolumn{2}{|c|}{ Less severe liver disease Patients $(n=48)$} \\
\hline & n & $\%$ & $\mathbf{n}$ & $\%$ \\
\hline Actinic cheilitis & - & 0.0 & 1 & 2.1 \\
\hline Denture stomatitis & 1 & 5.5 & 1 & 2.1 \\
\hline Leukoplakia & - & 0.0 & 1 & 2.1 \\
\hline Ulcer & - & 0.0 & 2 & 4.2 \\
\hline HPV lesions & 1 & 5.5 & - & 0.0 \\
\hline Pigmentation & 3 & 16.5 & - & 0.0 \\
\hline Lichen planus & 1 & 5.5 & 1 & 2.1 \\
\hline Total & 6 & 33.3 & 6 & 12.6 \\
\hline
\end{tabular}

Table 2: Frequency of soft tissue lesions according to groups of disease severity in 66 chronic liver disease patients. 

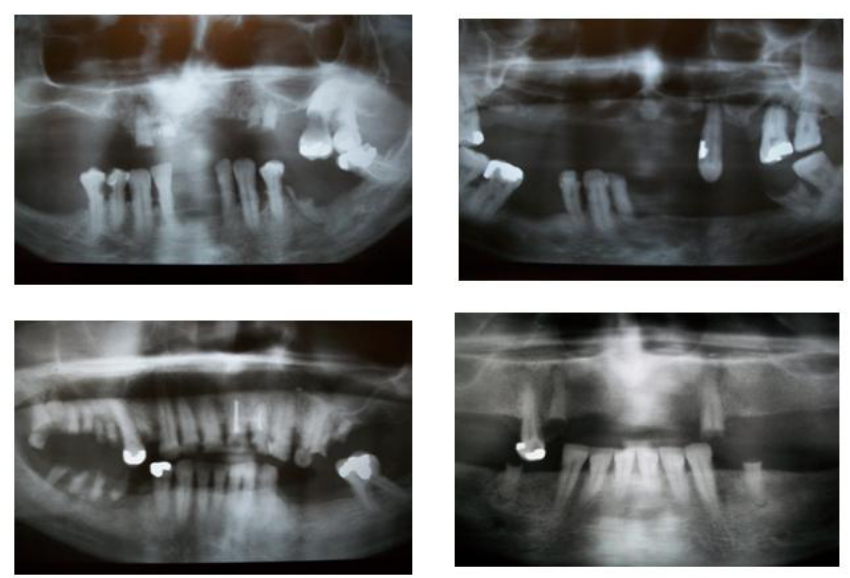

Figure 1: Panoramic Rx from LT patients, showing foci of oral infection.

by the hepatology team at the Transplant Clinic and Gastroenterology Service from Federal University of Bahia, which allows a proper assessment of liver and kidney function, and appropriate management of any arising complications. Dental treatment, coordinated in conjunction with the hepatology team, may be a factor that can improve survival rates in patients with severe liver disease [2].

The high frequency of a partially edentulous dental condition and periodontal disease, as well as the high DMFT index, demonstrated that cirrhotic patients on the transplant waiting list as well patients with less severe liver disease are far from meeting the global goal set for 2010 as established by the World Health Organization, which estimates that in an age range of 35-44 years, $96 \%$ of patients should present at least 20 functional teeth and less than $2 \%$ should be edentulous [24].

The evidence of soft tissue lesions indicates the need for stomatological examination in cirrhotic patients in order to prevent oral cancer which may develop due to trauma associated with poor hygiene, especially in cases where patients use dental prosthesis. The cases of stomatitis lesions in this study were associated with poor hygiene in dental prosthesis, which corroborates with findings in the literature associating poor hygiene with the proliferation of Candida albicans [6,25]. Literature reports a reduced salivary flow in patients with hepatitis $\mathrm{C}$, cirrhosis and those who underwent liver transplantation $[2,5,6]$. In this study, a decrease in salivary flow was observed in $71.2 \%$ of chronic liver disease patients, contributing to the development of caries, periodontal disease and other lesions in the oral mucosa. Concerning salivary glands, literature also describes the occurrence of HCV-related sicca syndrome ranging from 4 to $57 \%$ of chronic HCV carriers which may contribute to hypo salivation [26].

Gastroenterology and liver transplantation clinics in Brazil still do not offer an integrated dental treatment component in coordination with gastroenterology and transplant teams, making it necessary for the National Health System to require both dental care in an outpatient environment as well as hospitalization to perform dental surgery in the field of Surgery and Maxillofacial Traumatology. In outpatient hepatology clinics, where many patients are treated for viral hepatitis, there still exists a need for preventive actions to promote a better state of oral health in patients.

\section{Conclusion}

The present study has shown that, cirrhotic patients awaiting liver transplantation have poorer oral health status when compared with patients with less severe LD. HCV patients also have severe Periodontal Disease, requiring stomatological preventive intervention in patients with LD.

\section{References}

1. Caly WR, Strauss E (1993) A prospective study of bacterial infections in patients with cirrhosis. J Hepatol 18: 353-358.

2. Lins L, Bittencourt PL, Evangelista MA, Lins R, Codes L, et al. (2011) Oral health profile of cirrhotic patients awaiting liver transplantation in the Brazilian Northeast. Transplant Proc 43: 1319-1321.

3. Lins Kusterer, LEF (2011) Oral Diseases and Liver Pre and Post-Transplantation Disorders. J Transplant Technol Res S:1

4. Barbero P, Garzino Demo MG, Milanesio M, Ottobrielli A (1996) The denta assessment of the patient waiting for a liver transplant. Minerva Stomatol 45 431-439.

5. Díaz-Ortiz ML, Micó-Llorens JM, Gargallo-Albiol J, Baliellas-Comellas C Berini-Aytés L, et al. (2005) Dental health in liver transplant patients. Med Oral Patol Oral Cir Bucal 10: 66-76.

6. Guggenheimer J, Eghtesad B, Close JM, Shay C, Fung JJ (2007) Dental health status of liver transplant candidates. Liver Transpl 13: 280-286.

7. Reyna J, Richardson JM, Mattox DE, Banowsky LH, Nicastro-Lutton JJ (1982) Head and neck infection after renal transplantation. JAMA 247: 3337-3339.

8. Bassiri AG, Girgis RE, Theodore J (1996) Actinomyces odontolyticus thoracopulmonary infections. two cases in lung and heart-lung transplant recipients and a review of literature. Chest 109: 1109-1111.

9. Guggenheimer J, Mayer D, Egtesad B (2005) A survey of dental care protocols among US organ transplant centers. Clin Transplant 19: 15-18.

10. Wakefield CW, Throndson RR, Brock T (1995) Liver transplantation: dentistry is an essential part of the team. J Tenn Dent Assoc 75: 9-16.

11. Schmelzeisen R, Eckardt A, Knoll M, Girod S (1991) Special considerations in dental surgery procedures on organ transplantation patients. Dtsch Z Mund Kiefer Gesichtschir 15: 431-434.

12. Niederhagen B, Wolff M, Appel T, von Lindern JJ, Bergé S (2003) Location and sanitation of dental foci in liver transplantation. Transpl Int 16: 173-178.

13. Santos PSS, Pacheco MISS, Soler MPA, Felix VB (2011) Surgical dental treatment prior to liver transplantation. Braz J Oral Sci 10: 254-257.

14. Coelho JC, Parolin MB, Matias JE, Jorge FM, Canan Júnior LW (2003) Cause of late death in liver transplant recipients. Rev Assoc Med Bras 49: 177-180.

15. Coates EA, Brennan D, Logan RM, Goss AN, Scopacasa B, et al. (2000) Hepatitis $C$ infection and associated oral health problems. Aust Dent J 45: 108114.

16. Page RC, Elke PI (2007) Case definitions for use in population-based surveillance of periodontitis. J Periodontol 78: 1387-1399.

17. Leroy R, Eaton KA, Savage A (2010) Methodological Issues in epidemiological studies of periodontitis--how can it be improved? BMC Oral Health 10: 8.

18. Oral health surveys: Basic methods (1997) 4th edition. Geneva. World Health Organization.

19. Krasse B.(1988) Risco de cárie: um guia prático para avaliação e controle. Quintessence: São Paulo

20. Guggenheimer J, Moore PA. (2003) Xerostomia. Etiology, recognition and treatment. J Am Dent Assoc134:61.

21. Kinane DF, Chestnutt IG (2000) Smoking and periodontal disease. Crit Rev Oral Biol Med 11:356-365.

22. Olbrisch ME, Bendict SM, Ashe K, Levenson JL (2002) Psycological assessment and care of organ transplant patients. J Consult Clin Psychol 70 771

23. Ohyama H, Nakasho K, Yamanegi K, Noiri Y, Kuhara A, et al. (2009) An unusua autopsy case of pyogenic liver abscess caused by periodontal bacteria. Jpn J Infect Dis 62: 381-383.

24. World Health Organization (1994) Dental Caries Levels at 12 Years. WHO ORH (Oral Health)/EIS (Epidemiological Information System)/12-year-old book. Geneva: WHO. 
Citation: Lins L, Pereira Falcao AF (2012) Oral Health Status of Cirrhotic Patients in List of Liver Transplantation and of Viral Hepatitis Carriers. J Transplant Technol Res 2:116. doi:10.4172/2161-0991.1000116

25. Webb BC, Thomas CJ, Willcox MD, Harty DW, Knox KW (1998) Candidaassociated denture stomatitis. Aetiology and management: a review. Part 1. Factors influencing distribution of Candida species in the oral cavity. Aust Dent J 43: $45-50$
26. Ko HM, Hernandez-Prera JC, Zhu H, Dikman SH, Sidhu HK, et al. (2012) Morphologic Features of Extrahepatic Manifestations of Hepatitis C Virus Infection. Clin Dev Immunol 2012:740138. 